\title{
Reactor User Interface Technology Development Roadmaps for a High Temperature Gas-cooled Reactor Outlet Temperature of $750^{\circ} \mathrm{C}$
}

The INL is a

U.S. Department of Energy

National Laboratory

operated by

Battelle Energy Alliance

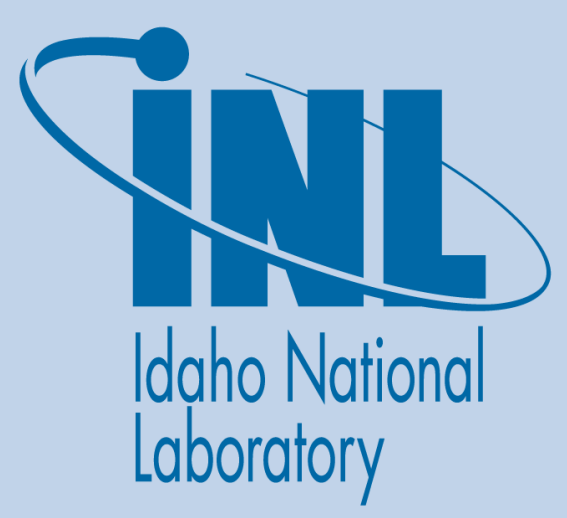

December 2010

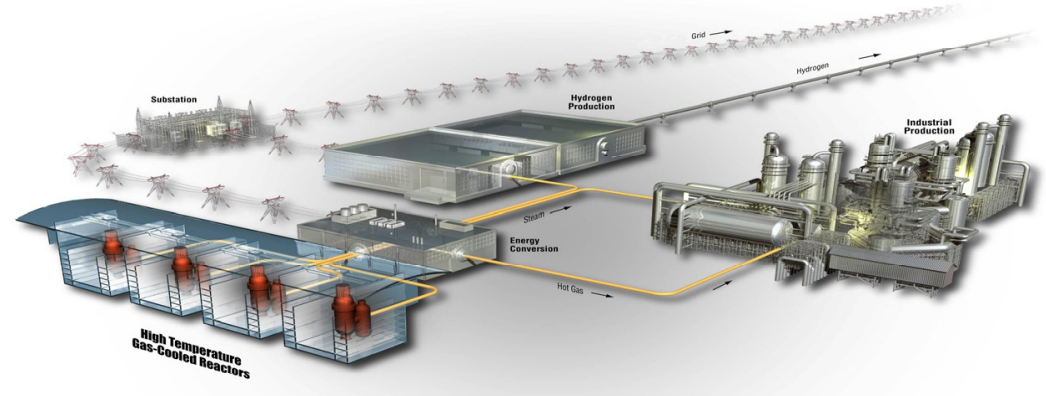




\section{DISCLAIMER}

This information was prepared as an account of work sponsored by an agency of the U.S. Government. Neither the U.S. Government nor any agency thereof, nor any of their employees, makes any warranty, expressed or implied, or assumes any legal liability or responsibility for the accuracy, completeness, or usefulness, of any information, apparatus, product, or process disclosed, or represents that its use would not infringe privately owned rights. References herein to any specific commercial product, process, or service by trade name, trade mark, manufacturer, or otherwise, does not necessarily constitute or imply its endorsement, recommendation, or favoring by the U.S. Government or any agency thereof. The views and opinions of authors expressed herein do not necessarily state or reflect those of the U.S. Government or any agency thereof. 


\section{Reactor User Interface Technology Development Roadmaps for a High Temperature Gas-cooled Reactor Outlet Temperature of $750^{\circ} \mathrm{C}$}

December 2010

Idaho National Laboratory Next Generation Nuclear Plant Project Idaho Falls, Idaho 83415

Prepared for the

U.S. Department of Energy

Office of Nuclear Energy

Under DOE Idaho Operations Office

Contract DE-AC07-05ID14517 
This page intentionally left blank. 
Next Generation Nuclear Plant Project

\section{Reactor User Interface Technology Development Roadmaps for a High Temperature Gas-cooled Reactor Outlet Temperature of $750^{\circ} \mathrm{C}$}

INL/EXT-10-20460

December 2010
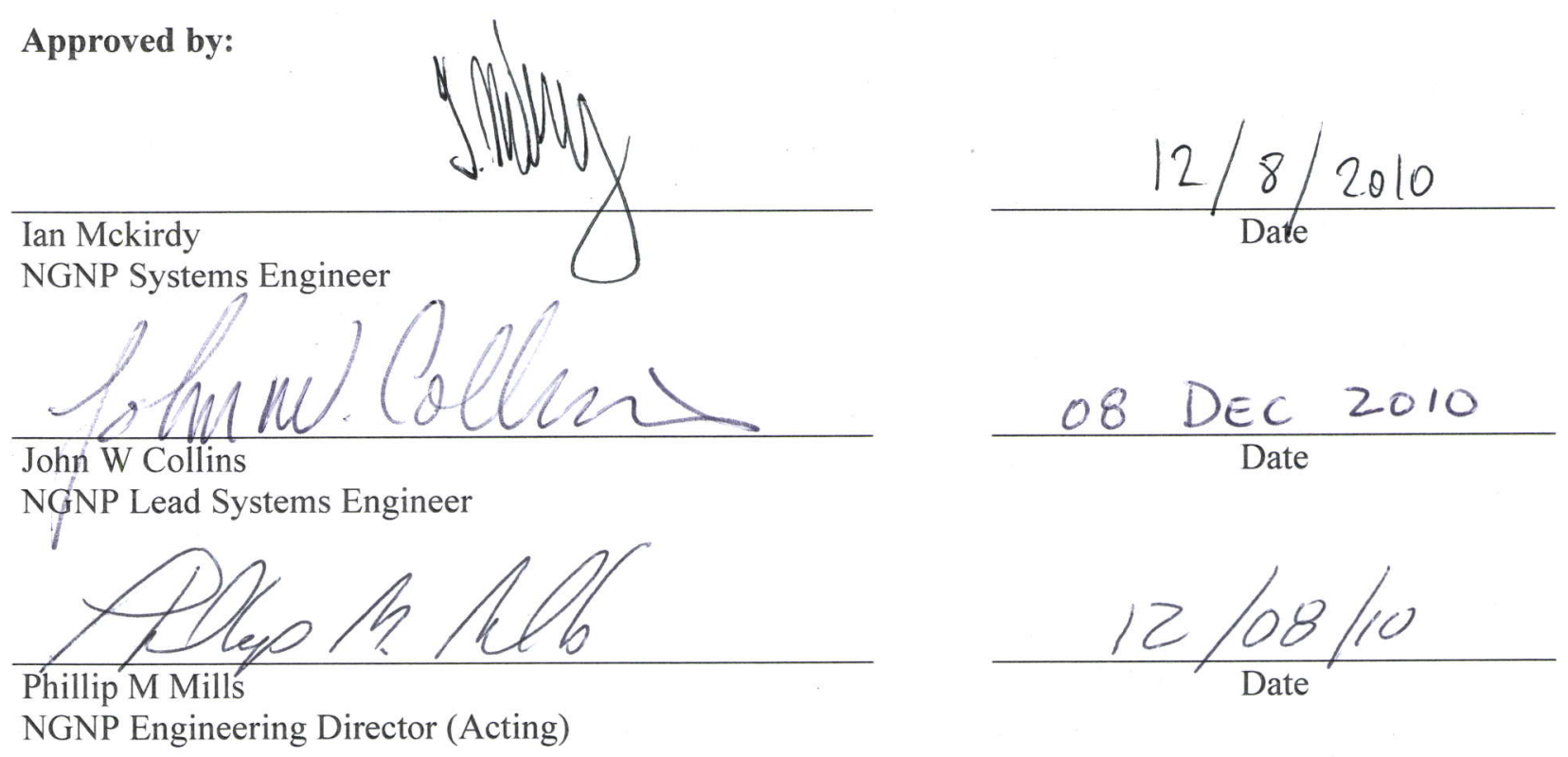
This page intentionally left blank. 


\section{EXECUTIVE SUMMARY}

This report documents an evaluation for the technology readiness of the interface components that are required to transfer high-temperature heat from a High Temperature Gas-cooled Reactor (HTGR) to selected industrial applications. This report assumes that the HTGR operates at a reactor outlet temperature of $750^{\circ} \mathrm{C}$ and provides electricity and/or process heat at $700^{\circ} \mathrm{C}$ to industrial applications, including the production of hydrogen.

Technology readiness of these interface components were assessed using an INL assessment process similar to that used to assess the technology readiness of the Next Generation Nuclear Plant (NGNP) Project (INL/EXT-09-16595). Through this assessment it was determined that the TRLs were sufficiently advanced that TDRMs were not needed. The Interface components can be designed and manufactured by commercial industry under existing rules found in the American Society of Mechanical Engineers (ASME) Boiler and Pressure Vessel (B\&PV) Code, Section VIII rules. Additional evaluations are recommended as the operating temperatures of the HTGR increase and as additional HTGR-integrated industrial applications are developed.

Using an HTGR to supply process heat to industrial applications is referred to as an HTGR-integrated process. An HTGR can produce steam, high-temperature heat that can be used for process heat, and/or electricity. In industrial applications, these products are generated by the combustion of fossil fuels (e.g., coal and natural gas), resulting in significant emissions of greenhouse gases, mainly carbon dioxide. Heat produced in an HTGR could be used to supply process heat to industrial applications without emitting carbon dioxide.

The industrial applications selected were based on a number of previously published INL Technical Evaluation (TEV) reports that have quantitatively modeled the technical, economic, and environmental advantages of integrating HTGRs into six specific industrial applications (See Appendix A for Block Flow Diagrams):

- Nuclear integrated natural gas to methanol to gasoline

- Nuclear integrated natural gas to liquids

- Nuclear integrated coal to liquids

- Nuclear integrated natural gas to ammonia

- Nuclear integrated natural gas to ammonia with high temperature steam electrolysis (HTSE)

- Oil sands recovery via steam assisted gravity drainage.

The results provided in the TEVs identified operating temperatures and pressures of the major unit operations and represent a feasibility study-level understanding of the HTGR-integrated industrial processes.

A series of workshops with the NGNP Project personnel were held to identify the major interfaces between the HTGR and the industrial applications. A systematic approach was taken to identify equipment that provides the interface between the HTGR and the Industrial Process as shown in Figure ES-1. Equipment used to support HTGR operations must meet more stringent design and operating requirements than equipment used to support operations in the interfaces and industrial processes. For example, a heat exchanger operating in the primary loop of the HTGR must meet ASME B\&PV Code, Section III rules. A heat exchanger operating in the interface for industrial process must meet ASME B\&PV Code, Section VIII rules. Section VIII rules allow for materials to be used at higher temperatures than Section III rules.

The technological development of the industrial applications process equipment is outside the scope of this report. 


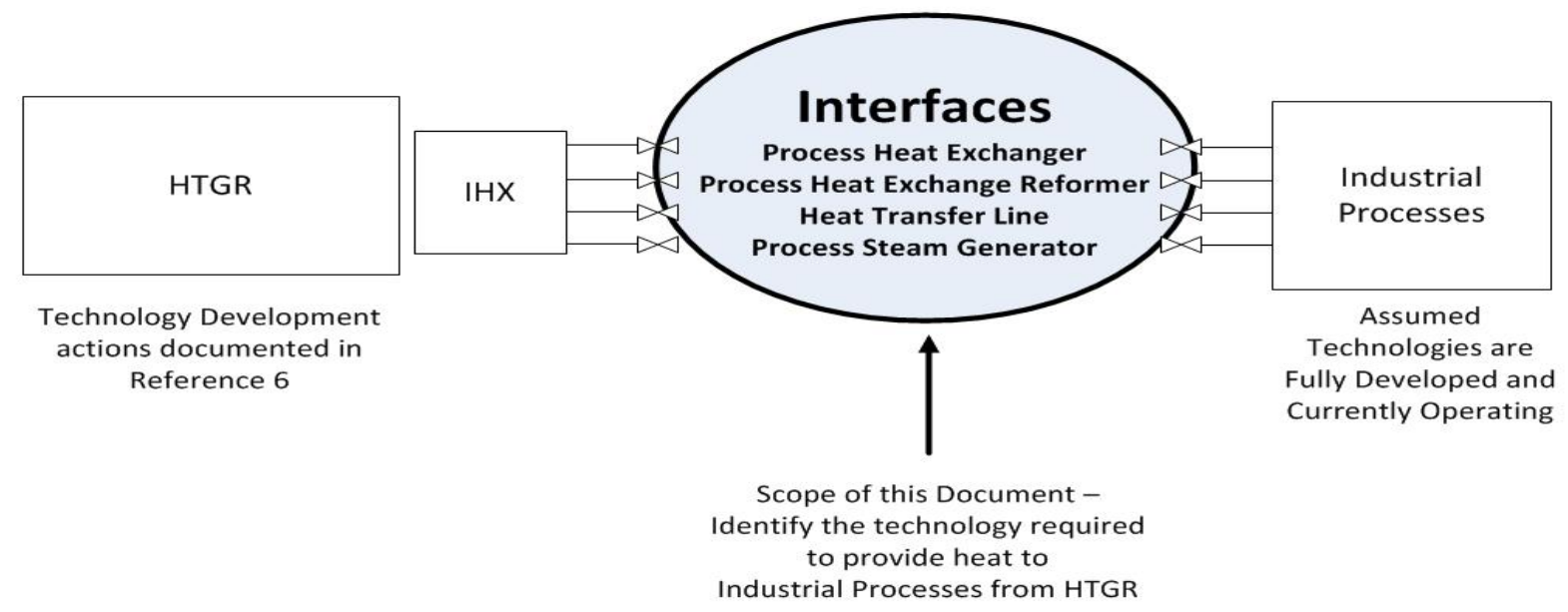

Figure ES-1. Integration of an HTGR into Industrial Processes.

The interface components were identified from the block flow diagrams and process models ( that were developed by the NGNP Project personnel) and incorporated into the TEVs referenced above. The criterion for selecting the interface equipment was to examine where the HTGR high temperature heat would be incorporated into the applicable industrial process. As the interface components were identified, a series of workshops were held with the engineering team to establish what those components would be and their operating environments and parameters.

In conjunction with these activities, literature searches were conducted to investigate what was currently commercially available to support the technology required for an HTGR interface. Also, a review of the ASME B\&PV Code, Section VIII rules was conducted to determine if the operating temperatures of the interface equipment were within the bounds of the applicable design rules. Following the workshops, literature searches and review of ASME B\&PV Code rules, the following conclusions and recommendations are made.

\section{Conclusions}

Due to the report finding that the TRLs for the components are sufficiently high to not require further technology development (at a Reactor Outlet Temperature of $750^{\circ} \mathrm{C}$ ), the development/investigation process was terminated.

Interface components can be designed and manufactured by commercial industry under existing American Society of Mechanical Engineers (ASME) Boiler and Pressure Vessel (B\&PV) Code, Section VIII rules.

\section{Recommendations}

As additional industrial applications are identified and evaluated, further technology evaluations are recommended to establish the technology readiness of the interface components.

As the HTGR outlet temperatures increase and the operating temperatures and pressures of the interface components increase, it is recommended that the technology readiness of interface components be reevaluated to ensure that equipment and design rules are available, or to assess the development needed to do so.

The selection of the heat transfer medium has not been finalized. Once the transfer medium has been selected, a design compatibility review needs to be conducted to determine whether additional technology development is needed. 


\section{CONTENTS}

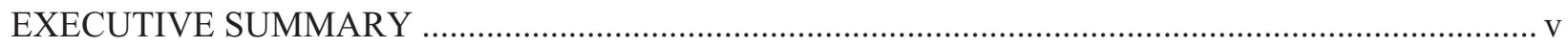

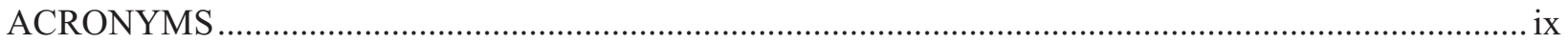

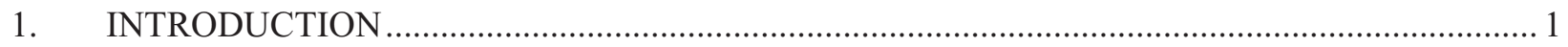

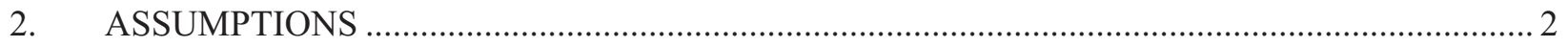

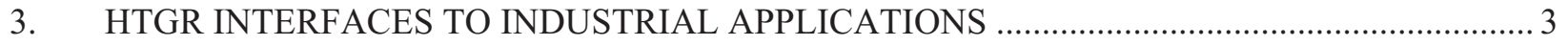

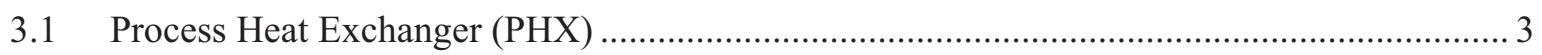

3.2 Process Heat Exchange Reformer (PHXR) ......................................................................... 4

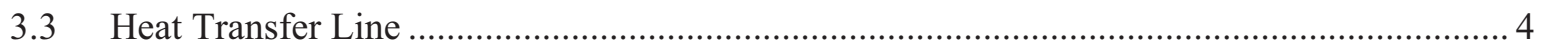

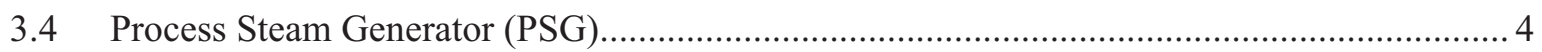

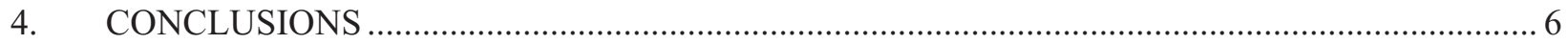

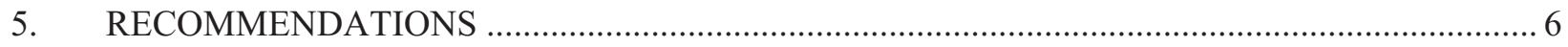

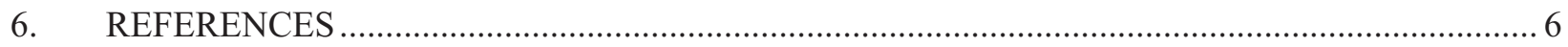

APPENDIX A Industrial Process Block Flow Diagrams .................................................................... 7

\section{FIGURES}

Figure A-1. Block flow diagram for the natural gas to methanol to gasoline process (TEV-667,

"Nuclear Integrated Methanol to Gasoline Production Analysis")... 8

Figure A-2. Block flow diagram for the natural gas to liquids process (TEV-672, "Nuclear Integrated Coal and Gas to Liquids Production Analysis").

Figure A-3. Block flow diagram for the coal to liquids process (TEV-672, "Nuclear Integrated Coal and Gas to Liquids Production Analysis"). 10

Figure A-4. Block flow diagram for the natural gas to ammonia with HTSE and cryogenic ASU process (TEV-666, "Nuclear Integrated Natural Gas to Ammonia Production Analysis").

Figure A-5. Block flow diagram for the Oil Sands Recovery via Steam Assisted Gravity Drainage process (TEV-704, "Nuclear Integrated Oil Sands Recovery via Steam Assisted Gravity Drainage").

Figure A-6. Block flow diagram for the natural gas to ammonia process (TEV 666, "Nuclear Integrated Natural Gas to Ammonia Production Analysis") ....

\section{TABLES}

Table 1. Interface components as used by the industrial applications. .5 
This page intentionally left blank. 


\section{ACRONYMS}

ASME American Society of Mechanical Engineers

ASU Air Separation Unit

B\&PV Boiler and Pressure Vessel

DOE Department of Energy

GHG Green House Gas

GTL Gas to Liquids

HTGR High Temperature Gas-cooled Reactor

HTS Heat Transport System

HTSE High Temperature Steam Electrolysis

IHX Intermediate Heat Exchanger

INL Idaho National Laboratory

MTG Methanol to Gasoline

NGNP Next Generation Nuclear Plant

PHX Process Heat Exchanger

PHXR Process Heat Exchange Reformer

ROT Reactor Outlet Temperature

SAGD Oil Sands Recovery by Gravity Assisted Drainage

SHTS Secondary Heat Transport System

TBD To Be Determined

TDRM Technology Development Roadmap

TRL Technology Readiness Level 
This page intentionally left blank. 


\section{Reactor User Interface Technology Development Roadmaps}

\section{INTRODUCTION}

This report identifies the interface components required to transfer high-temperature heat from a High Temperature Gas-cooled Reactor (HTGR) to a number of industrial applications. This report assumes that the HTGR operates at a reactor outlet temperature of $750^{\circ} \mathrm{C}$ and provides electricity and/or process heat at $700^{\circ} \mathrm{C}$ to industrial applications, including hydrogen production.

HTGRs operate at high temperatures and provide enhanced safety features, allowing for placement within close proximity to industrial applications beyond electricity production. The Next Generation Nuclear Plant Project was established based on a DOE Generation IV research and development evaluation completed in 2003 to integrate high temperature reactor technology with advanced hydrogen, electricity and process heat production capabilities. The project was authorized by the Energy Policy Act of 2005.

Using an HTGR to supply process heat to industrial applications is referred to as an HTGR-integrated industrial process. An HTGR can produce steam, high-temperature heat that can be used for process heat, and/or electricity. The use of the HTGR technology as a source of heat would replace the combustion of fossil fuels in many of these applications, for example the conversion of coal to synthetic fuels and chemical process feedstock. HTGR technology can improve the U.S. energy supply by (1) reducing reliance on imports, (2) reducing the energy price volatility that has been experienced over the last few decades (e.g., wide swings in the prices of oil, natural gas, and coal), and (3) extending the life of nonrenewable energy resources for more productive and efficient uses where no current alternatives are available. As a non- $\mathrm{CO}_{2}$ emitting substitute for the burning of fossil fuels, HTGRs can offset significant quantities of industry-generated $\mathrm{CO}_{2}$ emissions and other greenhouse gases (GHG).

Heat produced in an HTGR could be used to supply process heat to industrial applications without emitting carbon dioxide. HTGRs can be designed to supply the following to an industrial process:

- Process heat of $700^{\circ} \mathrm{C}$ at a pressure of 6 to 9 megapascals $(\mathrm{MPa})^{\mathrm{a}}$

- Heat output of 600 megawatts thermal (MWth) per HTGR module

- $\quad$ Steam at $540^{\circ} \mathrm{C}$ and $17 \mathrm{MPa}$

- Electricity.

The industrial applications evaluated were based on a number of previously published Idaho National Laboratory (INL) Technical Evaluation (TEV) reports (Ref. 1-4) that have quantitatively modeled the environmental, technical, and economical advantages of integrating HTGRs into the following six specific industrial applications:

\footnotetext{
${ }^{a}$ Should their supply parameters not meet the intended application, design modifications can be considered; for example, the HTGR could support the delivery of a higher temperature process heat up to $950^{\circ} \mathrm{C}$ and multiple HTGR's can be used together to supply a power requirement $>600$ MWth.
} 
- Nuclear integrated natural gas to methanol to gasoline - Block Flow Diagrams Appendix A, Figure A-1

- Nuclear integrated gas to liquids - Block Flow Diagrams Appendix A, Figure A-2

- Nuclear integrated coal to liquids - Block Flow Diagrams Appendix A, Figure A-3

- Nuclear integrated natural gas to ammonia with high temperature steam electrolysis (HTSE) - Block Flow Diagrams, Appendix A, Figure A-4

- Oil Sands Recovery via Steam Assisted Gravity - Block Flow Diagrams, Appendix A Figure A-5.

- Nuclear integrated natural gas to ammonia (TEV-666) - Block Flow Diagrams Appendix A, Figure A-6

The 'Nuclear integrated coal to liquid' and the 'Nuclear integrated natural gas to ammonia with high temperature steam electrolysis' industrial applications had an interface to an HTSE unit. They were the only interface components identified for those applications. The technological development of the interface components are detailed in the HTSE project (Ref. 5) and are not in the scope of this document. The technological development of the industrial applications process equipment is outside the scope of this report.

Technology readiness of these interface components were assessed using an INL assessment process similar to that used to assess the technology readiness of the Next Generation Nuclear Plant Project (Ref. 6). Through this assessment it was determined that the TRLs were sufficiently advanced that TDRMs were not needed. Interface components can be designed and manufactured by commercial industry under existing American Society of Mechanical Engineers (ASME) Boiler and Pressure Vessel (B\&PV) Code, Section VIII rules (Ref. 7). Additional evaluations are recommended as the operating temperatures of the HTGR increase and as additional HTGR-integrated industrial applications are developed.

\section{ASSUMPTIONS}

The following assumptions were made in the investigation of the components required to interface an HTGR to industrial applications:

1. The reactor operates at an outlet temperature of $750^{\circ} \mathrm{C}$ and delivers process heat at $700^{\circ} \mathrm{C}$ at a pressure of 6 to $9 \mathrm{MPa}$.

2. The issue of tritium migration from the HTGR will be resolved from both a technical and regulatory perspective upstream of the industrial processes.

3. The technological development process for the delivery of hydrogen to industrial applications is handled by the High Temperature Steam Electrolysis (HTSE) program. 


\section{HTGR INTERFACES TO INDUSTRIAL APPLICATIONS}

An interface component enables the transfer of high temperature heat from an HTGR to an industrial application. The process of identifying the interface components was to examine each industrial application and see where an HTGR could be used to supply heat to one or more process steps that currently use the burning of fossil fuels for their energy needs. The interface points where HTGR nuclear heat would be applied became the focus areas that would require further study for technological development.

The interface points were identified from the process models developed by the NGNP Project personnel that were incorporated into the TEVs referenced above. As the focus areas and interface points were identified, a series of workshops were held with the engineering team to establish what those components would be and their operating environments and parameters. There were four types of interface components identified to transfer the process heat from an HTGR to the industrial applications reviewed in this report:

- Process heat exchanger (PHX)

- Process heat exchange reformer (PHXR)

- Heat transfer line

- $\quad$ Process steam generator (PSG).

In conjunction with these activities, literature searches were conducted to investigate what can currently be designed and manufactured by commercial industry to support the technology required for an HTGR interface. Also, a review of the ASME B\&PV Code, Section VIII rules was conducted to determine if the operating temperatures of the interface equipment were within the bounds of the applicable design rules. Following the workshops, literature searches and review of ASME B\&PV Code rules, it was determined that the TRLs were sufficiently advanced that TDRMs were not needed. Interface components are commercially available and will be designed under existing ASME B\&PV Code, Section VIII rules. Additional evaluations are recommended as the operating temperatures of the HTGR increase and as additional HTGR-integrated industrial applications are developed.

\subsection{Process Heat Exchanger (PHX)}

The PHX gas-to-gas convective heat exchanger accepts heat from the secondary heat transfer loop from the HTGR intermediate heat exchanger (IHX) and transfers it to the respective process units. The PHX transfers heat between the secondary heat transport system (SHTS) and its process units. The SHTS is supplied from the IHX and is used to transfer heat to downstream applications via a secondary heat medium working fluid. The PHX is comprised of the following components:

- Heat exchanger cores and/or modules containing heat transfer surfaces

- The PHX vessel

- Headers and/or piping that provide a transition between the heat exchanger core and/or modules and the SHTS piping

- Thermal baffles and insulation.

The primary function of the PHX is to contain secondary heat medium coolants and to transport thermal energy, in the form of heat, from the SHTS working fluid. Secondary functions include providing a pressure boundary and insulating the vessel.

A typical industrial application for the PHX would be: 
1. Preheating the inlet feeds for process units to a temperature compatible for the process unit reactions (sulfur removal, reformers, etc.).

2. Reboiler duty to provide heat for the dispersal of hydrocarbon liquids as a vapor for distillation in a distillation column.

\subsection{Process Heat Exchange Reformer (PHXR)}

The PHXR accepts heat from the secondary heat transfer loop from the HTGR IHX and transfers it to the respective process units. The PHXR transfers heat between the SHTS and its process units. The SHTS is supplied from the IHX and is used to transfer heat to downstream applications via a secondary heat medium working fluid. The PHXR is comprised of the following components:

- Refractory lined reformer vessel

- Catalyst bed

- Heat exchanger cores and/or modules containing the heat transfer surface

- Headers and/or piping that provide a transition between the heat exchanger core, process gas inlet/outlet and/or modules, and the SHTS piping

- Thermal baffles and insulation.

The primary function of the PHXR is to contain secondary thermal coolants and transport thermal energy, in the form of heat, from the SHTS working fluid such that the heat is maintained to support the reforming activities. Secondary functions include providing a pressure boundary and insulating the vessel.

A typical industrial application for the PHXR would be the heat exchange reforming processes, which reacts steam with fossil fuels (e.g., steam methane reformer to make hydrogen) at high temperatures.

\subsection{Heat Transfer Line}

The heat transfer line component is a pipeline that can transfer high temperature and pressure heat over long distances without significant degradation of temperature or pressure. The heat transfer line consists of high temperature and pressure piping, heat recirculators, and heat control valves.

The heat transfer line delivers high temperature heat from an HTGR to industrial processes that require high temperature process heat. The transfer line must retain the pressure and temperature such that there is not a significant reduction in the energy being delivered to the process downstream.

\subsection{Process Steam Generator (PSG)}

The PSG converts water into steam from a heat source, in this case the heat transferred from the IHX. The PSG produces saturated steam at temperatures up to $540^{\circ} \mathrm{C}$. One of the industrial applications identified in this report — oil sands recovery via steam assisted gravity drainage (SAGD) — uses the steam generator to inject steam into a horizontal well to reduce the viscosity of the bitumen making the extraction of the bitumen easier. 
Table 1. Interface components as used by the industrial applications.

\begin{tabular}{|c|c|c|c|}
\hline Component & Industrial Application & Description & \begin{tabular}{|c|} 
Temperature/ \\
Pressure Range
\end{tabular} \\
\hline $\begin{array}{l}\text { Process heat } \\
\text { exchanger } \\
(\mathrm{PHX})\end{array}$ & $\begin{array}{l}\text { Natural gas to methanol to } \\
\text { gasoline - Appendix A, } \\
\text { Figure A-1 } \\
\text { Natural gas to liquids - } \\
\text { Appendix A, Figure A-2 } \\
\text { Natural gas to ammonia- } \\
\text { Appendix A, Figure A-6 }\end{array}$ & $\begin{array}{l}\text { The PHX heat exchanger accepts } \\
\text { heat from the secondary heat } \\
\text { transfer loop from the HTGR } \\
\text { IHX and transfers it to the } \\
\text { respective process units. } \\
\text { Main purpose is to preheat the } \\
\text { inlet feeds for process units such } \\
\text { that the incoming gas or steam } \\
\text { feeds are at a temperature } \\
\text { compatible for the process unit } \\
\text { reactions. }\end{array}$ & $\begin{array}{l}350 \text { to } 700^{\circ} \mathrm{C} \\
3 \text { to } 12 \mathrm{MPa}\end{array}$ \\
\hline $\begin{array}{l}\text { Process heat } \\
\text { exchange } \\
\text { reformer } \\
\text { (PHXR) }\end{array}$ & $\begin{array}{l}\text { Natural gas to methanol to } \\
\text { gasoline - Appendix A, } \\
\text { Figure A-1 } \\
\text { - Natural gas to ammonia - } \\
\text { Appendix A, Figure A-6 }\end{array}$ & $\begin{array}{l}\text { The PHXR accepts heat from the } \\
\text { secondary heat transfer loop } \\
\text { from the HTGR IHX and } \\
\text { transfers it to the respective } \\
\text { process units. } \\
\text { Main purpose is heat exchange } \\
\text { reforming processes, which react } \\
\text { steam at high temperature with } \\
\text { fossil fuels (e.g., steam methane } \\
\text { reformer to make hydrogen). }\end{array}$ & $\begin{array}{l}550 \text { to } 700^{\circ} \mathrm{C} \\
3 \text { to } 8 \mathrm{MPa}\end{array}$ \\
\hline $\begin{array}{l}\text { Heat transfer } \\
\text { line }\end{array}$ & $\begin{array}{l}\text { Oil sands recovery via } \\
\text { steam assisted gravity } \\
\text { drainage - Appendix A, } \\
\text { Figure A-5 }\end{array}$ & $\begin{array}{l}\text { The heat transfer line component } \\
\text { is a pipeline that can transfer } \\
\text { high temperature and pressure } \\
\text { heat over long distances without } \\
\text { significant degradation of } \\
\text { temperature or pressure. The } \\
\text { heat transfer line consists of high } \\
\text { temperature and pressure heat } \\
\text { loop piping, heat recirculators } \\
\text { and heat control valves. }\end{array}$ & $\begin{array}{l}300 \text { to } 700^{\circ} \mathrm{C} \\
7 \mathrm{Mpa}\end{array}$ \\
\hline $\begin{array}{l}\text { Process steam } \\
\text { generator (PSG) }\end{array}$ & $\begin{array}{l}\text { Oil sands recovery via } \\
\text { steam assisted gravity } \\
\text { drainage - Appendix A, } \\
\text { Figure A-5 }\end{array}$ & $\begin{array}{l}\text { The PSG converts water into } \\
\text { steam from a heat source-in } \\
\text { this case the heat transferred } \\
\text { from the IHX. The steam } \\
\text { generator produces saturated } \\
\text { steam up to } 540^{\circ} \mathrm{C} \text {. }\end{array}$ & $540^{\circ} \mathrm{C}$ \\
\hline
\end{tabular}




\section{CONCLUSIONS}

Due to the report finding that the TRLs for the components are sufficiently high to not require TDRMs (at reactor outlet temperature of $750^{\circ} \mathrm{C}$ ), the development/investigation process was terminated.

Interface components can be designed and manufactured by commercial industry under existing American Society of Mechanical Engineers (ASME) Boiler and Pressure Vessel (B\&PV) Code, Section VIII rules.

\section{RECOMMENDATIONS}

As additional applications are identified and evaluated, further technology evaluations are recommended to establish the technology readiness of the interface components.

As the HTGR outlet temperatures increase and the operating temperatures and pressures of the interface components increase, it is recommended that the technology readiness of interface components be reevaluated to ensure that equipment is available.

The heat transfer medium has not been finalized. Once the transfer medium has been selected, a design compatibility review needs to be conducted to determine whether additional technology development is needed.

\section{REFERENCES}

1. TEV-667, "Nuclear-Integrated Methanol-to Gasoline Production Analysis," Rev. 1, dated 5/15/2010.

2. TEV-672, "Nuclear Integrated Coal and Gas to Liquids Production Analysis," Rev. 1, dated $5 / 12 / 2010$.

3. TEV-666, "Nuclear Integrated Ammonia Production Analysis," Rev. 2, dated 5/26/2010.

4. TEV-704, "Nuclear Integrated Oil Sands Recovery via Steam Assisted Gravity Drainage," Rev. 1, dated 5/12/2010.

5. TEV-693, "Nuclear Integrated Hydrogen Production Analysis," Rev. 1, dated 5/15/2010.

6. INL/EXT-09-16598 "Next Generation Nuclear Plant Project Technology Development Roadmaps: The Technical Path forward for 750-800 ${ }^{\circ} \mathrm{C}$ Reactor Outlet Temperature," Rev. 0, dated August 2009.

7. ASME Boiler and Pressure Vessel Code, American Society of Mechanical Engineers, the 2010 Edition. 


\section{APPENDIX A}

Industrial Process Block Flow Diagrams 


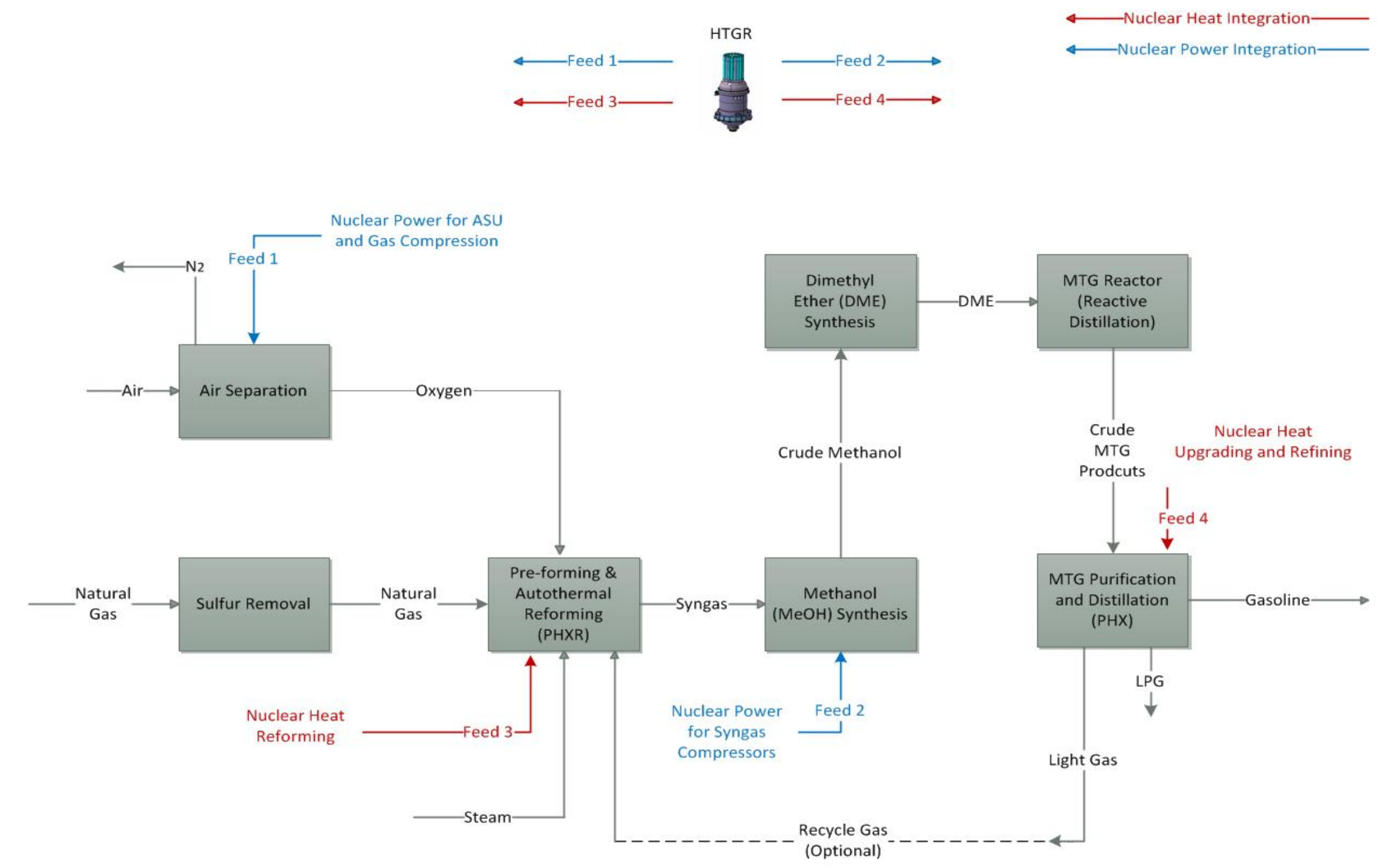

Figure A-1. Block flow diagram for the natural gas to methanol to gasoline process (TEV-667, "Nuclear Integrated Methanol to Gasoline Production Analysis") 


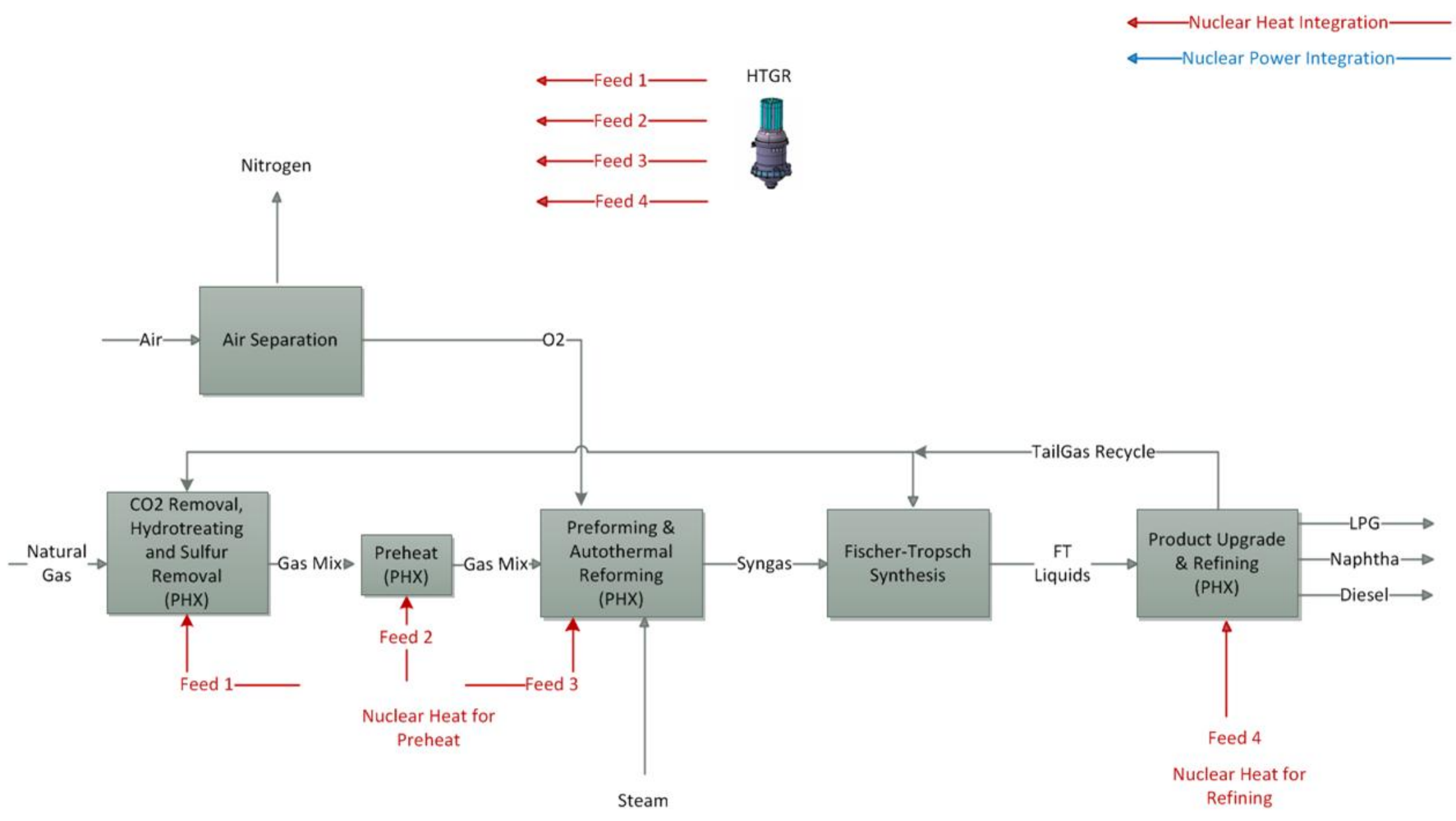

Figure A-2. Block flow diagram for the natural gas to liquids process (TEV-672, "Nuclear Integrated Coal and Gas to Liquids Production Analysis"). 


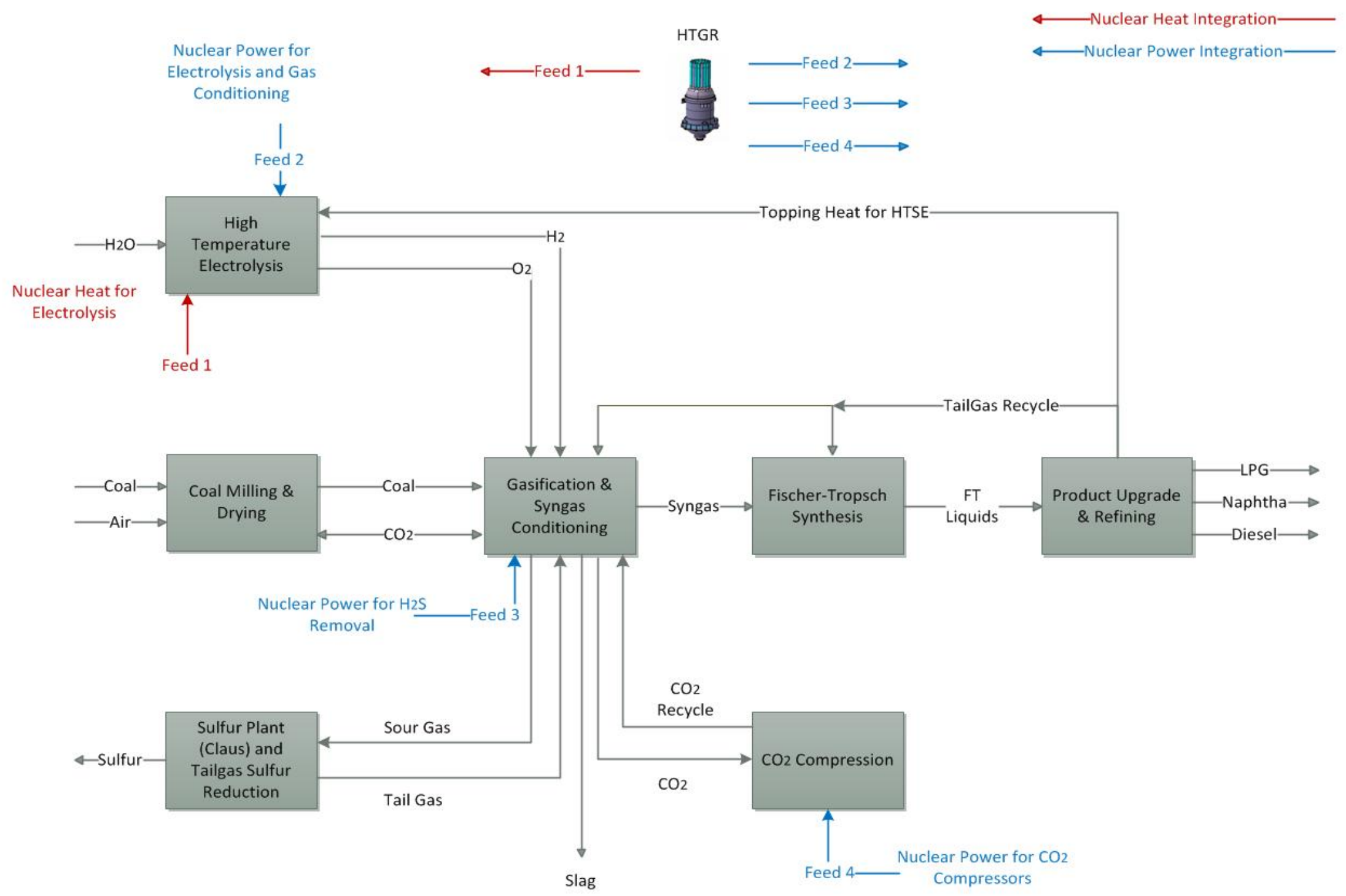

Figure A-3. Block flow diagram for the coal to liquids process (TEV-672, "Nuclear Integrated Coal and Gas to Liquids Production Analysis"). 


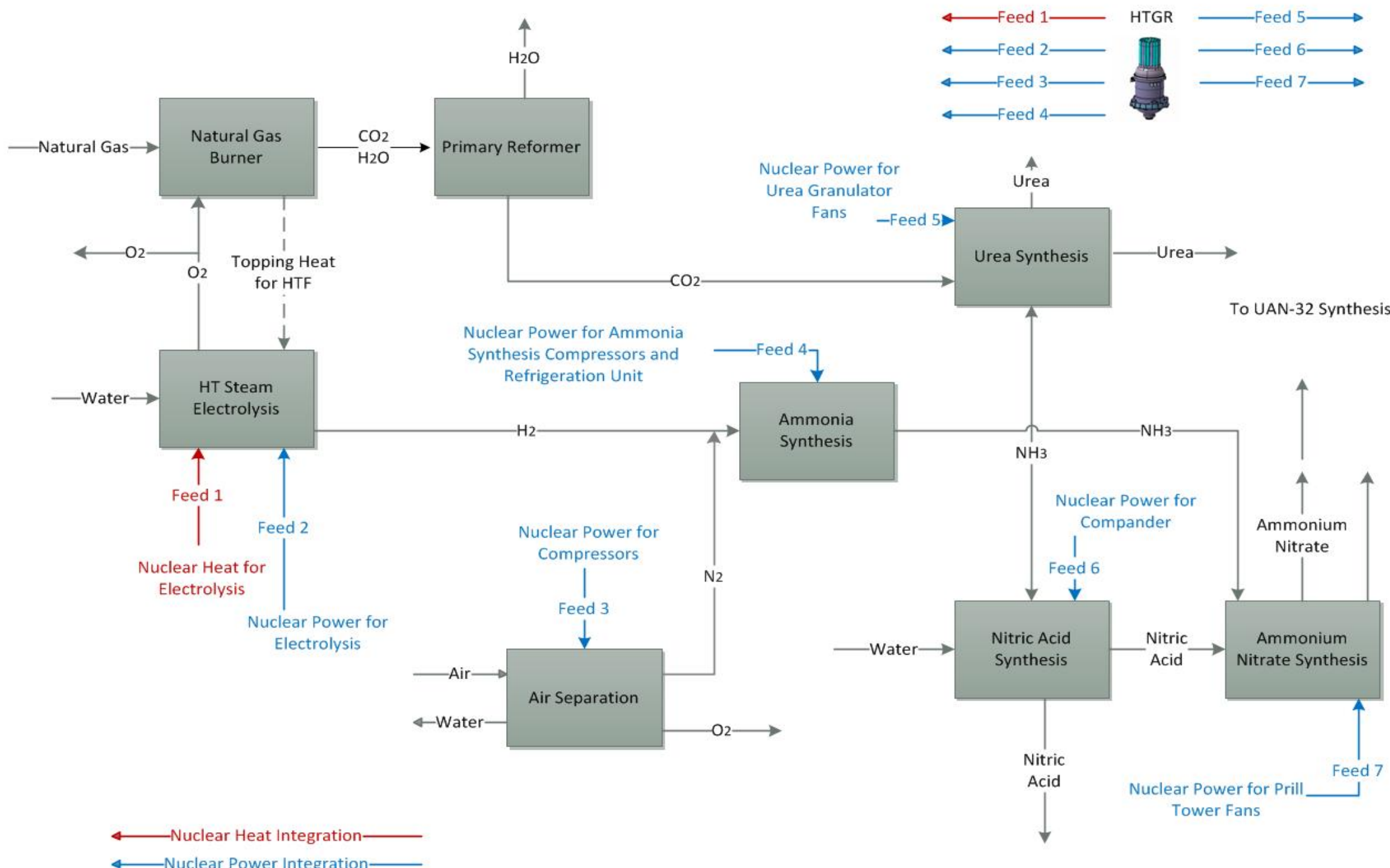

Figure A-4. Block flow diagram for the natural gas to ammonia with HTSE and cryogenic ASU process (TEV-666, "Nuclear Integrated Natural Gas to Ammonia Production Analysis"). 


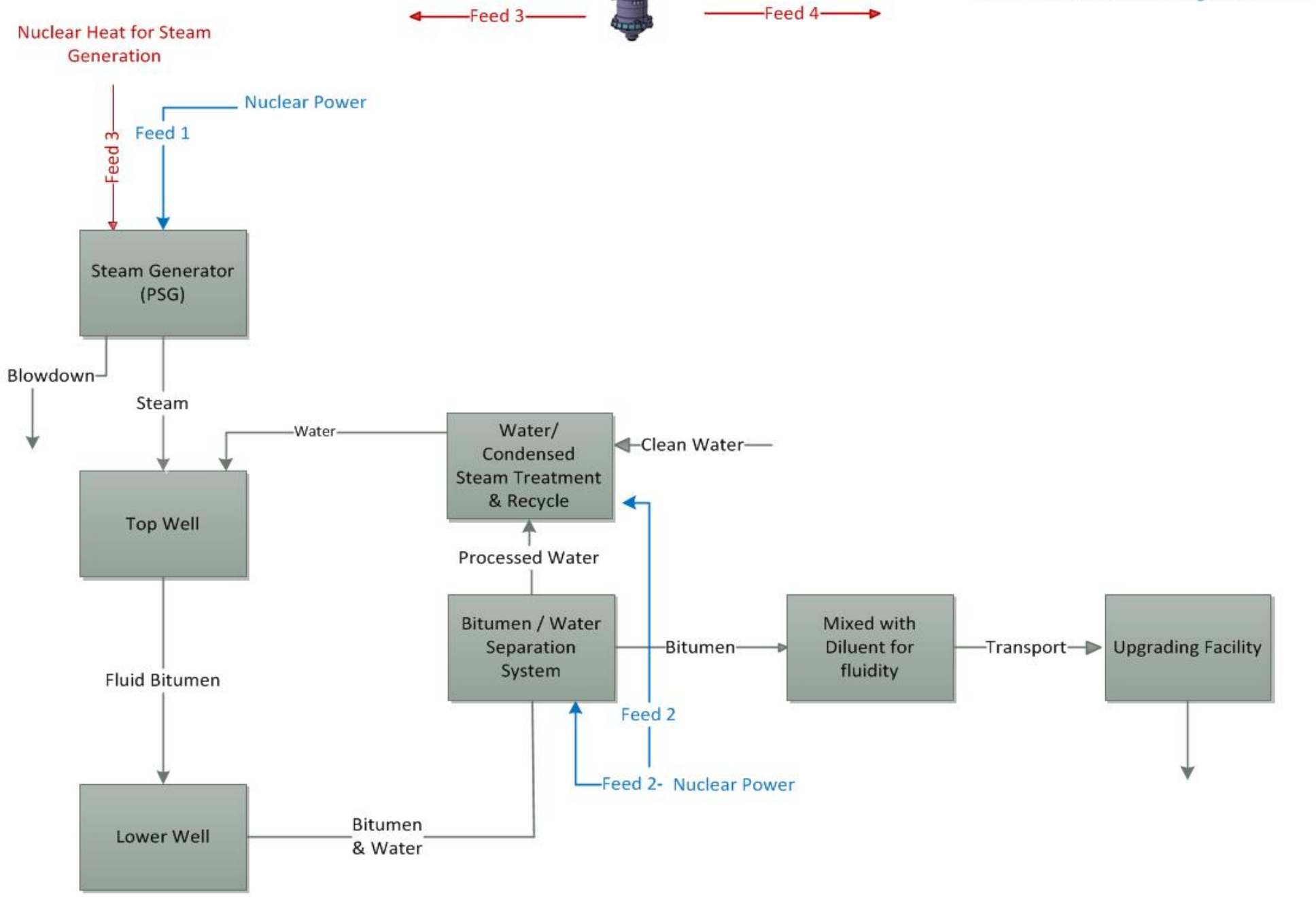

Figure A-5. Block flow diagram for the Oil Sands Recovery via Steam Assisted Gravity Drainage process (TEV-704, "Nuclear Integrated Oil Sands Recovery via Steam Assisted Gravity Drainage"). 
Nuclear Heat for Natural Gas Preheat

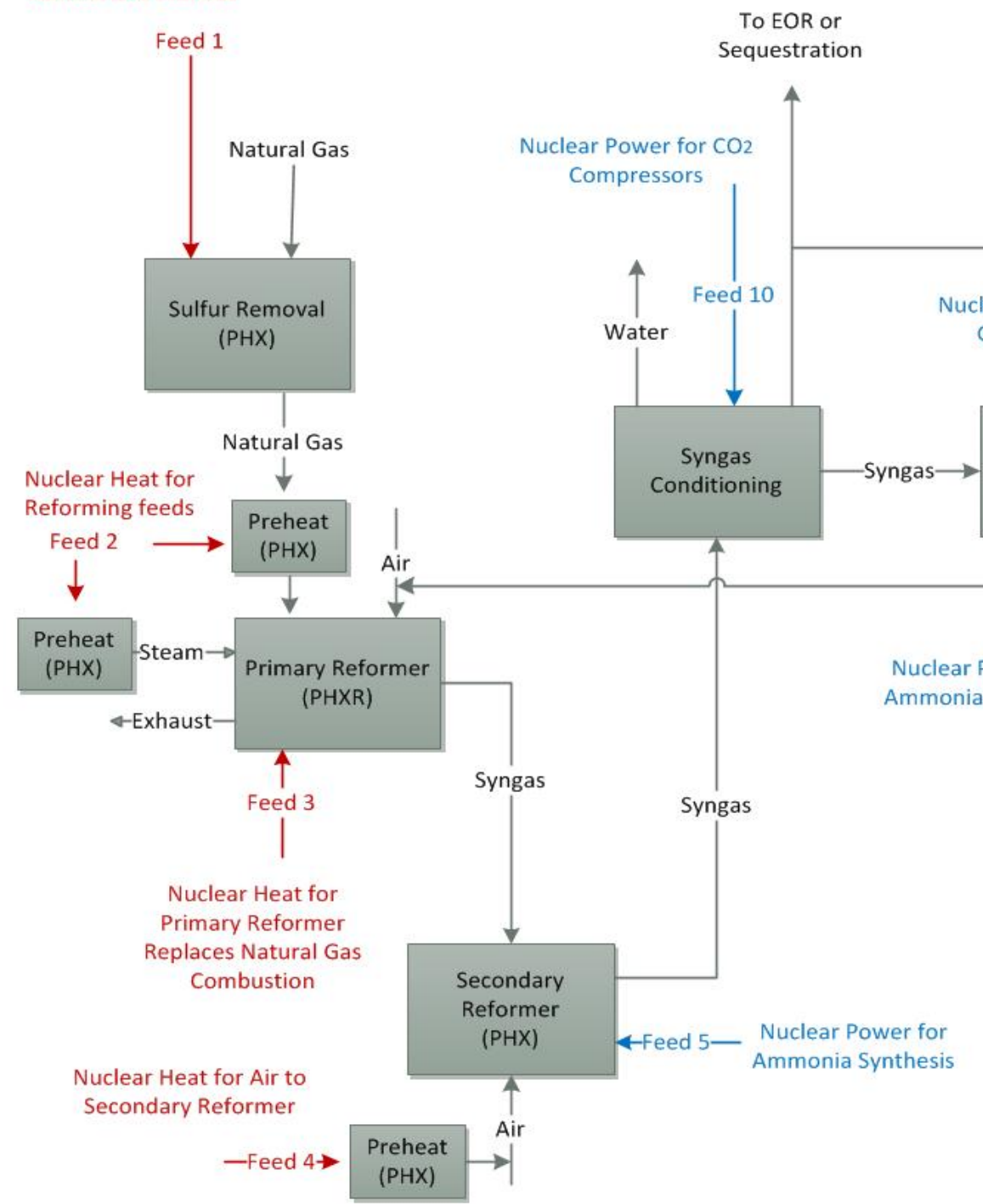

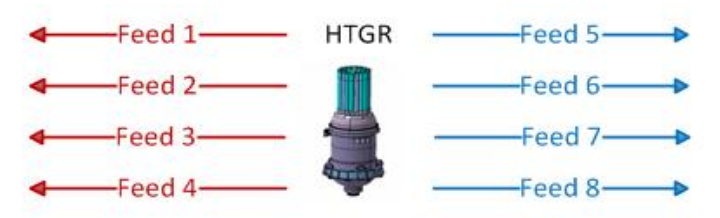
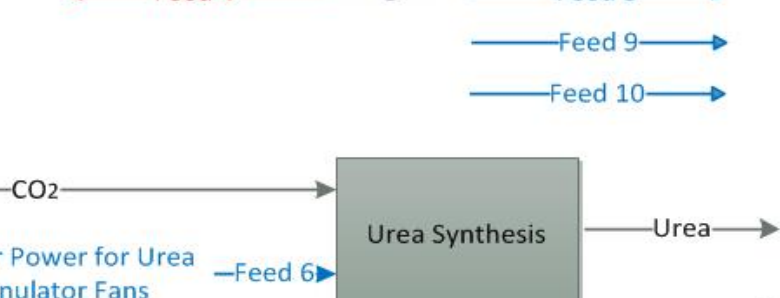

Granulator Fans

Feed 6

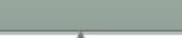

To UAN-32 Synthesis

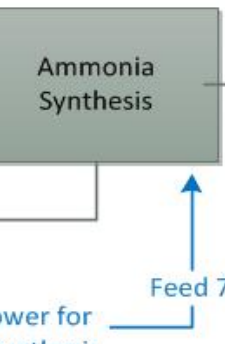
reed 7

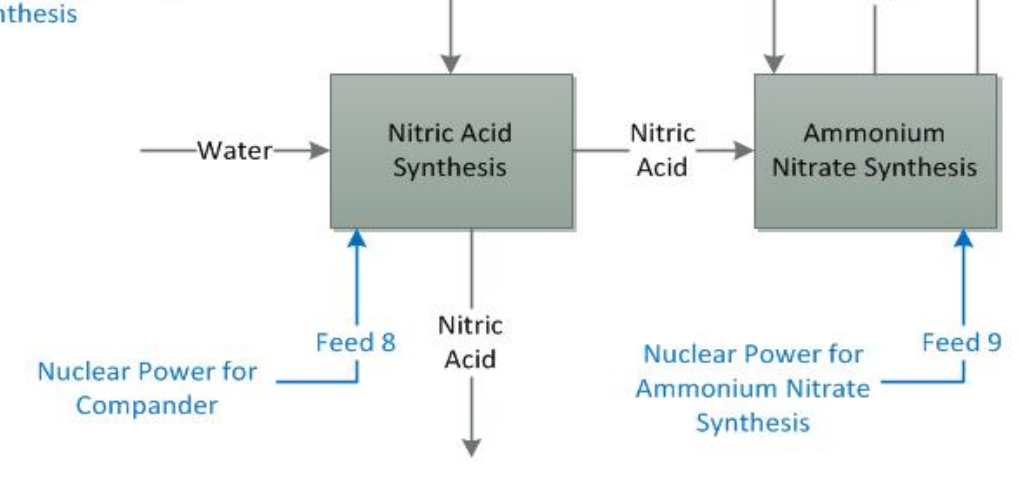

$\longleftarrow$ Nuclear Heat Integration-

$\longleftarrow$ Nuclear Power Integration-

Figure A-6. Block flow diagram for the natural gas to ammonia process (TEV 666, "Nuclear Integrated Natural Gas to Ammonia Production Analysis") 